http://jmscr.igmpublication.org/home/ ISSN (e)-2347-176x ISSN (p) 2455-0450

crossref DOI: https://dx.doi.org/10.18535/jmscr/v7i8.132

\author{
Journal Of Medical Science And Clinical Research \\ IGM Publication \\ An Official Publication of IGM Publication
}

\title{
Experience of Phyllodes tumors of breast treated in tertiary health care centre
}

\author{
Authors \\ Ritesh Dhanbhar ${ }^{1}$, Niranjan Dash ${ }^{2}$
}

\begin{abstract}
Objective: This study was performed to determine the incidence of phyllodes tumor, its pathological subtypes and characteristics in terms of recurrence.

Methodology: This is prospective observational study. This study includes patients of age >40years with breast lump treated in our institute. Study was carried out from $1^{\text {st }}$ February 2017 to $31^{\text {th }}$ January 2019. In this study 106 patients were enrolled. Patients' demographic data, pathology reports and recurrence during 6 month follow up were analyzed.

Results: Breast tumor is common on left side. Out of 106 patients, 94 patients (88.67\%) had carcinoma breast, 8 patients (7.5\%) had phyllodes tumor and 4 patients (3.77\%) had fibroadenoma. Among the phyllodes tumor cases $62.5 \%$ tumours were benign, $25 \%$ tumours were borderline, and $12.5 \%$ tumours were malignant. Three patient had local recurrence and one had metastatic disease. Out of these recurrences one was having phyllodes tumor with metastatic disease.

Conclusion: Phyllodes tumours are rare, locally aggressive and mostly benign breast tumors with significant good survival and cure rates.
\end{abstract}

\section{Introduction}

Phyllodes tumor, previously known as cystosarcoma phyllodes, account for $0.5 \%$ to $1.0 \%$ of all breast tumors and $2.5 \%$ of all fibroepithelial tumors. ${ }^{(1,2)}$ Phyllodes tumor arises from mesenchymal cells, hence these tumors are pathologically distinguished from adenocarcinoma of the breast. $^{(2)}$ Phyllodes tumours are histologically classified by World Health Organization (WHO) as benign (35\%-64\%), borderline (12\%-- 20\%), and malignant (10\%$30 \%){ }^{(3)}$ Malignant phyllodes tumor tend to recur and metastasize at a higher frequency than the other forms of phyllodes tumor. ${ }^{(4)}$ Surgical excision with negative surgical margins is the mainstay of treatment and is associated with relatively high disease-free survival and long term survival rates and a low recurrence rate.

$(5,6)$ Radiation therapy is often used because phyllodes tumor tends to be locally aggressive. ${ }^{(7,8)}$

\section{Methodology}

This is prospective observational study. This study includes patients of age >40years with breast lump treated in our institute. Study was carried out from $1^{\text {st }}$ February 2017 to $31^{\text {th }}$ January 2019. Patients were enrolled in the study after they provided verbal informed consent. In this study 106 patients were enrolled. In all patients preoperatively FNAC was done. Patients with carcinoma of breast were treated by modified radical mastectomy. Patients with phyllodes tumor were treated by wide local excision. Patients of 
fibroadenoma treated by excision. Patient's demographic data, tumor characteristics and pathology reports were analyzed. Patients were followed up to six month for recurrence following surgery.

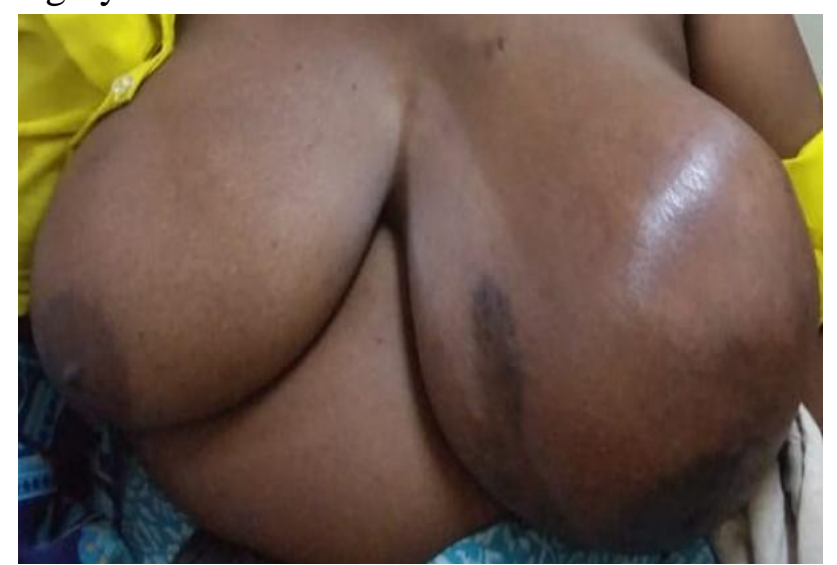

Fig. No. 1: Preoperative photograph of Phyllodes tumor patient
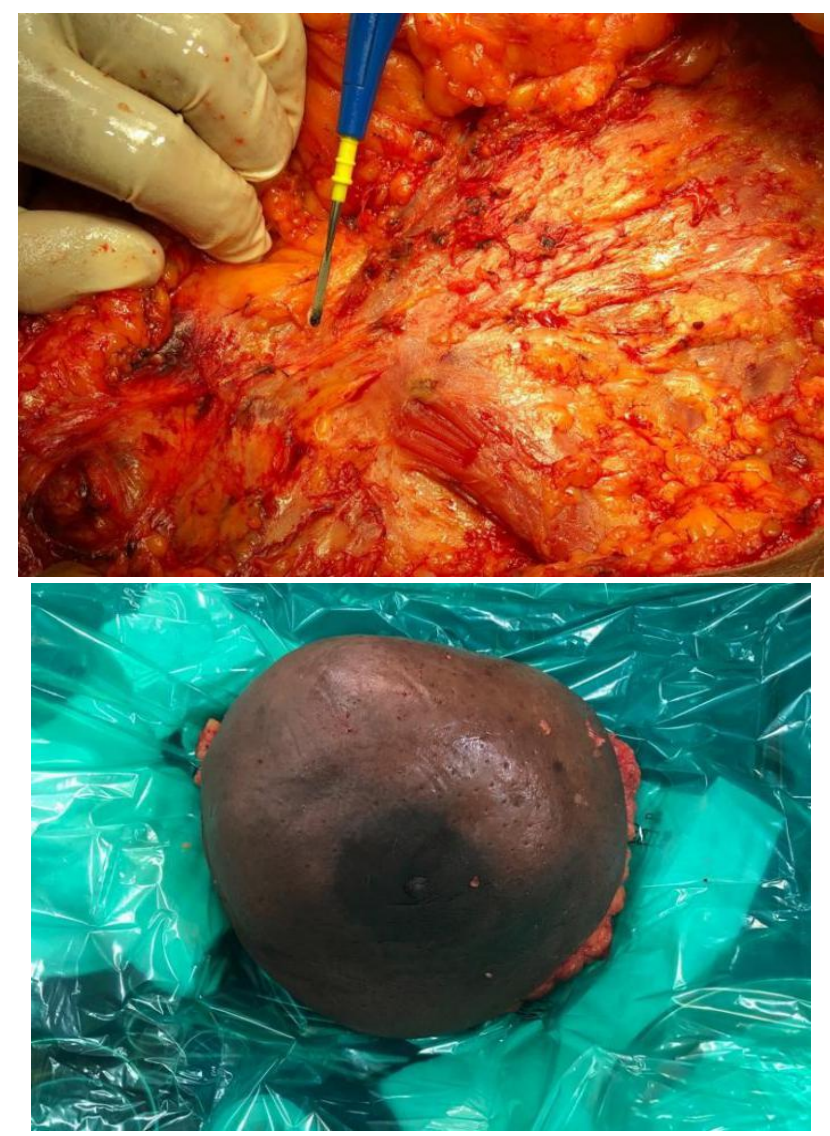

Fig. no. 2: Intraoperative photograph of large phyllodes tumor of size $18 \mathrm{~cm}$

\section{Results}

\section{1) Demography}

In this study 106 patients were enrolled. Their median age was 51years. Only four patients had a history of previous cancer of breast. Two patients had family history of breast cancer. None of the patients had previously received radiotherapy. Only one patient had a history of oral contraceptive pill use and none had used hormonal replacement therapy (Table No. 1). The patients in the study had a mean of two pregnancies.

Table No. 1: Patient characteristics

\begin{tabular}{|l|c|}
\hline Patient characteristics & Patient No. \\
\hline History of cancer & $4(3.8 \%)$ \\
\hline Family history of breast cancer & $2(1.9 \%)$ \\
\hline Oral contraceptive pill use & $1(0.9 \%)$ \\
\hline History of ionizing radiation & 0 \\
\hline
\end{tabular}

\section{2) Breast tumor side}

Out of 106 patients, 72 patients $(67.92 \%)$ had left breast tumour, 32 patients $(30.18 \%)$ had right breast tumour, and 2 patients $(1.88 \%)$ had bilateral breast tumour (Table No. 2).

Table No. 2: Breast tumour side

\begin{tabular}{|l|c|}
\hline Breast tumour side & Patient No. \\
\hline Left & $72(67.92 \%)$ \\
\hline Right & $32(30.18 \%)$ \\
\hline Bilatral & $2(1.88 \%)$ \\
\hline
\end{tabular}

\section{3) Tumor Pathology}

Out of 106 patients, 94 patients $(88.67 \%)$ had carcinoma breast, 8 patients $(7.5 \%)$ had phyllodes tumor and 4 patients $(3.77 \%)$ had fibroadenoma. (Table No. 3) Among phyllodes tumor cases $62.5 \%$ tumours were benign, $25 \%$ tumours were borderline, and $12.5 \%$ tumours were malignant (Table No. 4 ).

Table No. 3 Type of tumour

\begin{tabular}{|l|c|}
\hline Type of tumour & Patients No. \\
\hline Carcinoma & $94(88.67 \%)$ \\
\hline Phyllodes tumor & $8(7.5 \%)$ \\
\hline Fibroadenoma & $4(3.77 \%)$ \\
\hline
\end{tabular}

Table No. 4 : WHO Grading of Phyllodes tumor

\begin{tabular}{|l|c|}
\hline WHO Grading of Phyllodes tumor & Patients No. \\
\hline Benign & $5(62.5 \%)$ \\
\hline Borderline & $2(25 \%)$ \\
\hline Malignant & $1(12.5 \%)$ \\
\hline
\end{tabular}

\section{4) Recurrence}

Patients were followed up to six month for recurrence. Three patients $(2.83 \%)$ had local recurrence and one patient $(0.94 \%)$ had metastatic 
disease. Out of these recurrence cases, one $(0.94 \%)$ was having phyllodes tumor with metastatic disease. All three patients with recurrence had an adequate negative surgical margin at the first excision.

\section{Discussion and Review of Literature}

According to this study $7.5 \%$ of breast tumours are phyllodes tumours, which is more than Macdonald OK et al and Parker et al study, which states that phyllodes tumor accounts for $0.5 \%$ to $1.0 \%$ of all breast tumors and $2.5 \%$ of all fibroepithelial tumors. ${ }^{(1,2)}$

According to this study breast tumour is common on left side, similar result was seen in Hazem Assi et al study. ${ }^{(9)}$

WHO identified three types of phyllodes tumours on the basis of its pathological characteristics i. e. benign, borderline, and malignant. ${ }^{(10-12)}$ These types help to predict chances of development of local recurrence and metastatic disease. Mostly phyllodes tumours are benign (35\%-64\%).

In this study, among the phyllodes tumor cases $62.5 \%$ tumours were benign, $25 \%$ tumours were borderline, and $12.5 \%$ tumours were malignant . This finding is consistent with Reinfuss $M$ et al study which states that malignant tumors account for $10 \%$ to $30 \%$ of all phyllodes tumours. ${ }^{(4)}$

According to this study one patient $(0.94 \%)$ was having phyllodes tumor which was malignant in nature and had metastasis. This finding is consistent with Reinfuss $\mathrm{M}$ et al, Mitus $\mathrm{J}$ et aland Narayanakar RP et al study which states that malignant tumors of phyllodes tumor have a higher chance of recurrence and metastasis. $^{(4,13,14,15)}$

\section{Conclusion}

Phyllodes tumours are locally aggressive and mostly benign breast tumors with significant survival and cure rates. Breast conservative surgery and mastectomy are first line of treatment for such tumors. Despite the small sample size of our study population, it remains mostly consistent with the available literature regarding the epidemiology, tumor characteristics and treatment course of phyllodes tumor.

\section{References}

1. Macdonald OK, Lee CM, Tward JD, et al. Malignant phyllodes tumor of the female breast: association of primary therapy with cause-specific survival from the Surveillance, Epidemiology, and End Results (SEER) program. Cancer 2006; 107: 2127-2133.

2. Parker, SJ and Harries SA. Phyllodes tumours. Postgrad Med J 2001; 77: 428435.

3. World Health Organization. Histologic Typing of Breast Tumors. 2nd edition. Vol.2. Geneva, Switzerland: WHO; 1981.

4. Reinfuss M, Mitu\# s J, Duda K, et al. The treatment and prognosis of patients with phyllodes tumor of the breast: an analysis of 170 cases. Cancer 1996; 77: 910-916.

5. Pandey M, Mathew A, Abraham EK, et al. Primary sarcoma of the breast. J Surg Oncol 2004; 87: 121-125.

6. Fou A, Schnabel FR, Hamele-Bena D, et al. Long-term outcomes of malignant phyllodes tumors patients: an institutional experience. Am J Surg 2006; 192: 492495.

7. Barth RJ Jr, Wells WA, Mitchell SE, et al. A prospective, multi-institutional study of adjuvant radiotherapy after resection of malignant phyllodes tumors. Ann Surg Oncol 2009; 16: 2288-2294.

8. Gnerlich JL, Williams RT, Yao K, et al. Utilization of radiotherapy for malignant phyllodes tumors: analysis of the National Cancer Data Base, 1998-2009. Ann Surg Oncol 2014; 21: 1222-1230.

9. Hazem Assi et al. Phyllodes tumors of the breast treated in a tertiary health care center: case series and literature review. Journal of International Medical Research 2018; 0(0) 1-10. 
10. Treves $\mathrm{N}$ and Sunderland DA. Cystosarcoma phyllodes of the breast: a malignant and a benign tumor; a clinicopathological study of seventy-seven cases. Cancer 1951; 4: 1286-1332.

11. Norris HJ and Taylor HB. Relationship of histologic features to behavior of cystosarcoma phyllodes. Analysis of ninety-four cases. Cancer 1967; 20: 2090-2099.

12. Azzopardi JG, Ahmed A and Millis RR. Problems in breast pathology. Major Probl Pathol 1979; 11: i-xvi, 1-466.

13. Mitus J, Reinfuss M, Mitu\# s JW, et al. Malignant phyllodes tumor of the breast: treatment and prognosis. Breast J 2014; 20 : 639-644.

14. Narayanakar RP, Gangaiah DM, Althaf S, et al. Cystosarcoma phyllodes: pathological enigma: a retrospective review of 162 cases. Indian J Cancer 2015; 52: 365-368.

15. Kim S, Kim JY, Kim DH, et al. Analysis of phyllodes tumor recurrence according to the histologic grade. Breast Cancer Res Treat 2013; 141: 353-363. 